\title{
A importância social, econômica e territorial do circuito inferior da economia urbana do eixo rodoviário Natal-Caicó, Rio Grande do Norte, Brasil
}

\author{
The social, economic and territorial importance of the urban economy lower circuit of the \\ road axis Natal-Caicó, Rio Grande do Norte, Brazil
}

\author{
Diego Salomão Candido de Oliveira Salvador \\ Professor do Programas de Pós-Graduação em Geografia da UFRN, Brasil \\ diegosalomao84@hotmail.com
}

\begin{abstract}
Resumo
Neste trabalho, objetivamos analisar a importância social, econômica e territorial das atividades não hegemônicas da economia urbana desenvolvidas no eixo rodoviário Natal-Caicó, estado do Rio Grande do Norte, Região Nordeste do Brasil. Nesse eixo, as cidades e a economia crescem alicerçadas, sobretudo, em atividades econômicas mantenedoras da pobreza estrutural produzida pela modernização do território, situação característica do processo de precarização do trabalho. Como resposta sistêmica, tem-se a segmentação da economia urbana, com o subsistema inferior cada vez mais dependente do superior, assim como mais permanente e receptor de trabalhadores. Por meio de reflexões sobre a teoria dos circuitos da economia urbana relacionadas com dados primários acerca das cidades do eixo Natal-Caicó, concluímos o trabalho sublinhando que, enquanto não predominar o mercado socialmente necessário, o circuito inferior é e será importante para viabilizar a sobrevivência da maioria dos trabalhadores e para explicitar a tensão ou a crise vivenciada no mercado de trabalho e na sociedade.
\end{abstract}

Palavras-chave: Economia urbana, Mercado de trabalho, Pobreza.

\begin{abstract}
In this study, we aimed to analyse the social, economic and territorial importance of hegemonic urban economy activities developed on the road axis Natal-Caicó, State of Rio Grande do Norte, Northeastern Brazil. In this axis, the cities and the economy grow based on supporters of poverty basic economic activities produced by the territory modernisation, situation characteristic of the precarious work process. As a systemic response, there is the urban economics segmentation, with the lower subsystem increasingly dependent on top, as well as more permanent and receiver. Through reflections on the theory of circuits of urban economics related to primary data about the road axis Natal-Caicó cities, we conclude the work stressing that, while not predominate the socially necessary market, the lower circuit is and it will be essential to make possible the survival of the majority of workers and to clarify the tension or the crisis experienced in the labour market and society.
\end{abstract}

Keywords: Urban economics, Labor market, Poverty. 


\section{INTRODUÇÃO}

Neste trabalho, objetivamos analisar a importância social, econômica e territorial das atividades desenvolvidas pelos pobres no eixo rodoviário Natal-Caicó, estado do Rio Grande do Norte, Região Nordeste do Brasil. Essa análise se justifica pelo fato de, no eixo rodoviário NatalCaicó, as cidades e a economia crescerem alicerçadas, sobretudo, em atividades econômicas mantenedoras da pobreza estrutural produzida pela modernização do território, situação essa característica do processo de precarização do trabalho. Como resposta sistêmica a essa situação, tem-se a segmentação da economia urbana, com o subsistema inferior cada vez mais dependente do superior, assim como mais permanente e receptor de trabalhadores diante da precarização das relações de trabalho e do desemprego, hoje, duradouro.

No Rio Grande do Norte existem quatro eixos rodoviários que macroestruturam o território (figura 1): o Natal-Fronteira Paraibana, utilizado para o transporte de passageiros e para o escoamento de balas, chapas plásticas, tecidos de algodão, granito, tungstênio e açúcar, em direção ao Porto de Suape e a Recife; o Natal-Macau, com utilização para transporte de passageiros e de carga de materiais de construção (brita, cal), combustível para aviação e automóveis bem como equipamentos para parque eólico; o Natal-Mossoró, utilizado para transporte de passageiros e de carga de frutas, castanha de caju, tecidos de algodão, produtos animais impróprios para alimentação humana, lagosta, peixes, camarão, tungstênio e balas, em direção ao Porto de Pecém, a Fortaleza e a Natal, e de sal, para abastecimento do mercado estadual ou regional, sendo que, para o escoamento desse produto, há uma importante conexão do eixo Natal-Mossoró com o Porto de Areia Branca; e o Natal-Caicó, com utilização, sobretudo, para o fluxo de passageiros, contudo também evidenciando o transporte de carga de produtos têxteis e alimentícios em pequena quantidade.

Adotamos o eixo rodoviário Natal-Caicó como recorte de análise devido ao fato desse subsistema de movimentos do território potiguar interligar municípios do interior e do litoral do estado, se destacar pelos fluxos intermunicipais de passageiros e se caracterizar por cidades cujo centro econômico importante é a rodovia que as atravessa, sendo a rodovia margeada, sobretudo, por diversas atividades da economia não hegemônica.

A análise que fazemos é fundamentada em reflexões sobre a teoria dos circuitos da economia urbana relacionadas com a interpretação de dados primários decorrentes de pesquisa de campo realizada no eixo rodoviário Natal-Caicó. Essa pesquisa foi realizada entre os meses de agosto de 2013 e janeiro de 2014, quando aplicamos questionário com 148 responsáveis por atividades não hegemônicas, cujos dados nos possibilitam refletir sobre a importância social, econômica e política da economia desenvolvida pelos agentes sociais não hegemônicos. 


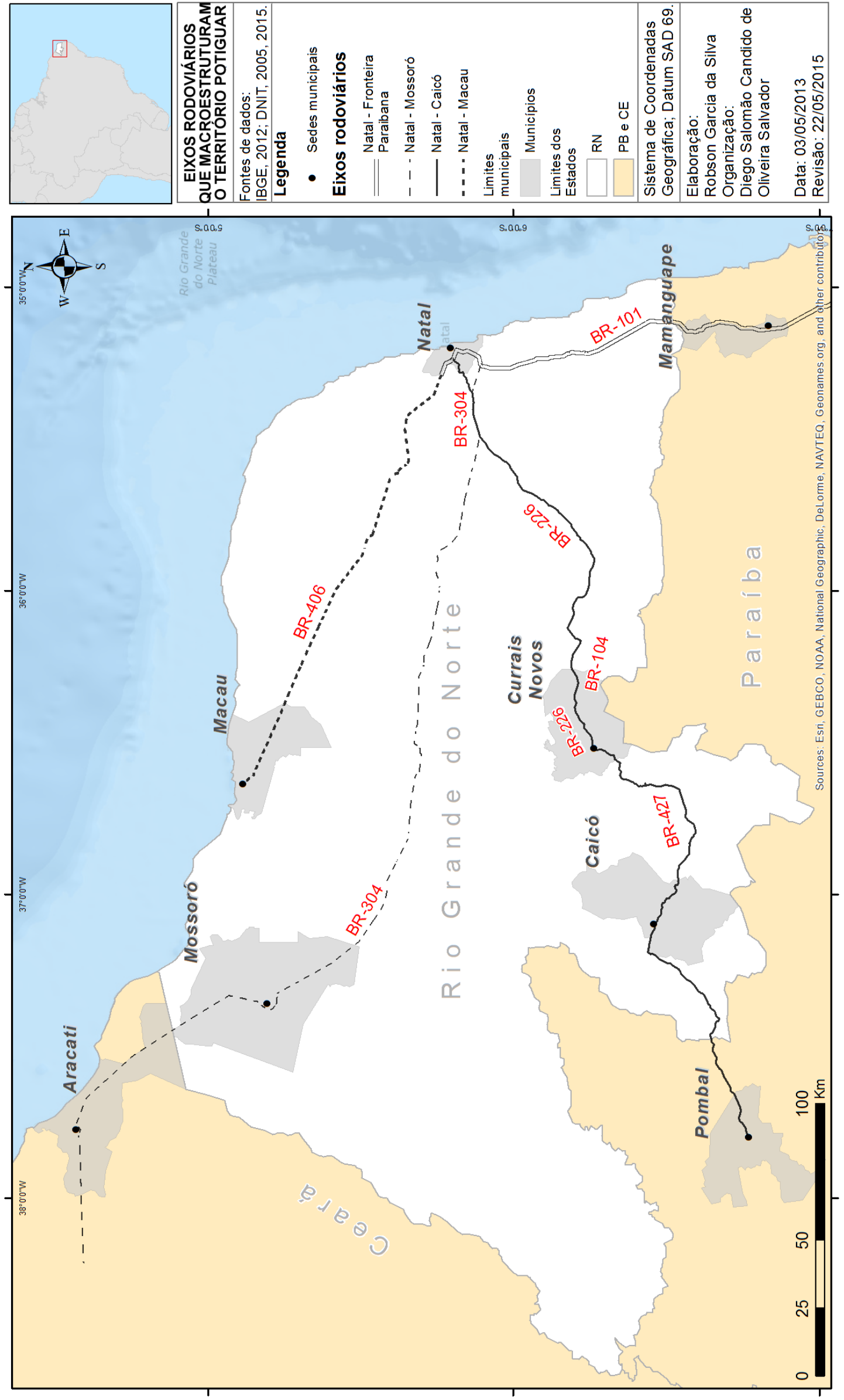

Figura 1 - Eixos rodoviários que macroestruturam o território potiguar

Cartografia: Robson Garcia da Silva, 2013. 


\section{REFLEXÕES SOBRE A TEORIA DOS CIRCUITOS DA ECONOMIA URBANA DOS PAÍSES SUBDESENVOLVIDOS}

As primeiras análises sobre a economia urbana dos países subdesenvolvidos datam das décadas de 1950 e 1960, alicerçadas na perspectiva da dualidade (BOEKE, 1953; LEWIS, 1954; GEERTZ, 1963; ARMSTRONG, McGEE, 1968; NUN, 1969; QUIJANO, 1969), considerando a existência da população e das atividades ditas informais à parte do crescimento capitalista.

A ruptura total com esse modelo analítico foi realizada ainda na década de 1970, por Oliveira (1972) e Santos (1978a). Oliveira, ao criticar o dualismo característico da abordagem da informalidade, assevera que a população e as atividades ditas informais não estão à parte do crescimento capitalista, mas, ao contrário, o integram e são importantes para sua dinâmica desigual e contraditória. Já Santos retomou pela base a teoria econômico-espacial das nações subdesenvolvidas, considerando as contribuições das concepções dualistas sobre a economia urbana dessas formações socioespaciais, mas avançando na apreensão da dinâmica dessa economia, com uma doutrina do desenvolvimento econômico em sua dimensão espacial: a teoria dos circuitos da economia urbana dos países subdesenvolvidos.

Estando de acordo com a compreensão de que a pobreza é relativa (ANDERSON, 1964), não devendo ser estudada homogeneamente ou segundo modelos analíticos que não se aplicam à interpretação de determinadas realidades e de que os pobres não são marginais econômica e politicamente (GUNDER FRANK, 1968), mas, sim, explorados do ponto de vista econômico e oprimidos do político, Santos (1970) começou a formular a teoria dos circuitos da economia urbana dos países subdesenvolvidos pelo estudo das relações interurbanas em países de diferentes continentes do mundo. Aprofundando suas reflexões, chegou à consideração de que a cidade não é uma estrutura uniforme, mas um sistema urbano segmentado em dois subsistemas econômicos: o circuito superior e o circuito inferior. Ele assevera que esses subsistemas não existem separados, mas, ao contrário, coexistem e, desse modo, devem ser estudados de maneira interdependente, em variadas escalas geográficas: mundo, país, região, cidade (SANTOS, 1978a, 1978b).

Os circuitos da economia urbana são decorrentes da modernização econômica, assim como têm suas características relacionais e absolutas conectadas a esse processo. O subsistema superior é resultado direto da modernização, que, por sua seletividade territorial e desigualdade socioeconômica, tem como efeito indireto o subsistema inferior, fato que torna complexas as implicações do processo modernizador na organização do espaço e faz com que Santos (1972) sugira que, ao invés de se falar em modernização, trata-se de "modernizações", no plural e conectadas.

Ao destacar que ambos os circuitos decorrem do mesmo processo e coexistem no sistema urbano, Santos (1978a) fundamenta sua teoria na oposição dialética entre os subsistemas da 
economia urbana dos países subdesenvolvidos, tendo em vista que o funcionamento das atividades não hegemônicas ocorre de maneira complementar com atividades do circuito superior, bem como esse circuito subordina o subsistema inferior pela dominação da macroestrutura da economia e do território.

Foi pensando na segmentação da economia urbana dos referidos países que Santos optou por chamar os subsistemas econômicos de "circuitos", valorizando, assim, suas relações e a totalidade da estrutura econômica da cidade. Para McGee (1973), tal denominação é bastante significativa para a análise da realidade urbana do mundo subdesenvolvido, pois caracteriza da melhor maneira possível os fluxos relacionais e internos existentes entre os subsistemas e dentro de cada um deles.

A teoria dos circuitos não dá conta apenas da complementaridade que marca a economia urbana dos países subdesenvolvidos, mas também da relação de exploração das atividades não hegemônicas por agentes hegemônicos do mercado (BIENEFELD, 1975), sendo que uma das funções essenciais do circuito inferior é contribuir para a reprodução ampliada do capitalismo, por meio da banalização do consumo entre os pobres, inclusive de produtos modernos, e pela submissão da poupança e da mais-valia desses agentes para o circuito superior, via sistemas financeiro, produtivo e de consumo. É por esse motivo que Santos (1978b, p. 51-52) diz atribuir as denominações "superior" e "inferior" aos circuitos.

Em suma, a teoria apresentada pelo citado geógrafo sul-americano é pioneira na ruptura com a abordagem dualista da economia urbana dos países subdesenvolvidos e, dentre outros aspectos importantes, possibilita que se analise a realidade dessas nações sem a necessidade de adotar modelos teóricos concatenados a histórias territoriais diferentes, evitando, desse modo, erros de interpretação bastante frequentes entre cientistas sociais e planejadores do espaço que costumam fundamentar suas práxis em ideias que não se aplicam ao lugar investigado ou ordenado.

Nos dias atuais, especificamente na geografia brasileira, cada vez mais pesquisadores vêm adotando a teoria dos circuitos para realizar análises da economia urbana nas mais variadas escalas geográficas do território nacional. Tal fato vem contribuindo para que essa teoria tenha sua importância teórico-metodológica destacada assim como para que determinadas reflexões e determinados aspectos evidenciados por Santos na década de 1970 sejam atualizados de acordo com os usos das variáveis-chave do período atual pelos agentes hegemônicos e pelos não hegemônicos.

Outrora, Santos (1978a) definiu o circuito inferior como sendo formado por atividades de pequena dimensão, bastante enraizadas no contexto em que estão, por manterem relações privilegiadas com a cidade ou a região que o abrigam e interessando principalmente à população pobre. 
Contemporaneamente, tal definição vem passando por alterações, devido a haver, em várias atividades desenvolvidas por pobres, incorporação de objetos técnicos modernos e de crédito financeiro, certa burocratização da organização, aumento da importância de capitais, propaganda do que é vendido ou ofertado, compra de objetos novos em substituição à reutilização de bens e aumento da escala de atuação no que tange à rede de mercadorias comercializadas ou utilizadas. Desse modo, o circuito inferior, nos dias atuais, pode ser definido como pequenas atividades cujos níveis de capital, tecnologia e organização vêm sendo alterados no sentido de maiores relações com o circuito superior da economia urbana, fato que também eleva a dependência daquele circuito a este. O desencadeamento do circuito inferior interessa tanto a pobres, que, por meio dele, obtêm ocupação e renda e têm a possibilidade de consumir, quanto a agentes do circuito superior, que o abastecem, ofertam crédito burocrático para seus agentes e enquadram suas atividades na formalização tributária.

Além dessa redefinição, é evidente, na atualidade, que as atividades do circuito inferior são híbridas quanto a objetos utilizados, apresentando, em sua organização, técnicas novas e técnicas antigas. Outrossim, o uso de variáveis-chave do período atual pela economia não hegemônica ocorre de modo mais denso em determinados territórios. Ao estudar o circuito inferior localizado em metrópoles brasileiras, Montenegro (2011) assevera que esse uso é mais denso nas áreas centrais de grandes cidades ou metrópoles, mas não se limita a essas áreas, ocorrendo também, com menor intensidade, em áreas periféricas de grandes ou médias cidades e em cidades locais.

Conforme as variáveis-chave do período atual - técnica, ciência, informação, consumo, finanças - e as características relacionais e absolutas dos circuitos da economia urbana nesse período, definimos estes circuitos no eixo rodoviário Natal-Caicó da seguinte maneira: o circuito superior constituído por atividades de organização burocrática, considerável nível tecnológico e forte necessidade de capital para seu desenvolvimento, como bancos, indústria, comércio e serviços modernos, e atacadistas. Tais atividades têm ampla escala de atuação, relacionando-se com os âmbitos regional, nacional e até mesmo global; o circuito inferior integrado por atividades de organização criativa e pouco ou nada burocrática, de tecnologia utilizada em nível inferior ao que ocorre naquele circuito e de menor necessidade de capital para o funcionamento, sendo, em contrapartida, imprescindível a intensidade de trabalho. É o caso das pequenas produções de alimentos, do pequeno comércio e dos serviços diversos fornecidos a varejo. As atividades não hegemônicas vêm, ultimamente, expandindo sua escala de atuação, contudo as relações com o lugar continuam importantes.

Há também atividades hegemônicas híbridas, isto é, que apresentam “[ [... a racionalidade instrumental, típica dos agentes hegemônicos, e a racionalidade comunicacional, típica dos agentes marginais" (BICUDO JÚNIOR, 2006, p. 14). Essas atividades formam o circuito superior marginal 
e são assim denominadas devido a apresentarem características do circuito superior e algumas do inferior. Ou seja, seu desenvolvimento envolve tanto a aplicação considerável de capital quanto a necessidade premente de trabalho, por vezes, familiar (SANTOS, 1978a). Além disso, no circuito superior marginal, a escala de atuação é bastante relacionada ao lugar, apesar de também haver conexões com outros contextos, como o microrregional e o estadual. Do mesmo modo, assim como no circuito inferior, as atividades superiores marginais são mais vulneráveis às situações de crise econômica, podendo desaparecer, aparecer ou serem reestruturadas mais rapidamente do que as puramente superiores (DAVID, 2010).

Com essas definições, inventariamos - na pesquisa de campo - 405 atividades do circuito superior no eixo rodoviário Natal-Caicó, destacando-se as seguintes: atividades financeiras, de seguros e serviços relacionados; comércio varejista de combustíveis para veículos automotores; comercialização de material de construção, artesanato, ração para animais; de tecidos, artigos de vestuário, calçados, plástico; de bijuteria, relógios, joias, óculos; serviço odontológico; comercialização de veículos, peças e motocicletas; produção de pré-moldados; produção de ração para gado; produção de artefatos de cerâmica e barro cozido para uso em construção; e atividades de advocacia, contabilidade, auditoria. Dessas, as que marcam mais acentuadamente o eixo são as de comercialização de combustíveis para veículos automotores (postos de combustíveis), as de comercialização de veículos, peças e motocicletas (lojas de venda de veículos e/ou motocicletas e lojas de venda, instalação e manutenção de peças para veículos e/ou motocicletas) e as atividades financeiras, de seguros e serviços relacionados (agências bancárias e postos bancários ou de correspondentes para realização de operações eletrônicas ou de empréstimos pessoais para aposentados, pensionistas e servidores públicos).

Das atividades do circuito superior do eixo rodoviário Natal-Caicó, a maioria são superiores marginais, por serem desenvolvidas com organização burocrática e considerável nível tecnológico, mas também se alicerçarem, por vezes, no trabalho familiar, além de sua escala de atuação ser, geralmente, local, microrregional e/ou estadual. Nos centros locais 1 , o circuito superior existente é predominantemente marginal, enquanto que, nos centros regionais sertanejos 2 e na

\footnotetext{
${ }^{1}$ Nosso entendimento de centro local é tributário da concepção de Santos (2008) sobre cidade local: aglomeração capaz de responder às necessidades vitais mínimas de dada população. Nessa perspectiva, asseveramos que a cidade local se apresenta como centro funcional imediato da área rural que a circunda, mas não como centro dinâmico da região que integra, devido a sua frágil complexidade funcional. No eixo rodoviário Natal-Caicó, as cidades que se caracterizam como centros locais são: Acari, Bom Jesus, Campo Redondo, Jardim do Seridó, Senador Elói de Souza, Serra Caiada e Tangará.

${ }^{2}$ Centros regionais sertanejos são importantes cidades do interior potiguar, que ofertam uma maior quantidade de bens e serviços e localizam serviços com melhor qualidade do que os encontrados nos centros locais, fatos que conectam suas funções à intermediação da produção e/ou do consumo na rede de relações urbanas. No eixo rodoviário Natal-Caicó, as cidades que se caracterizam como centros regionais sertanejos são: Caicó e Currais Novos, cidades principais da Região do Seridó Potiguar; e Santa Cruz, principal centro urbano da Região do Agreste Potiguar. Destacamos que as cidades de Macaíba e Parnamirim integram a Região Metropolitana de Natal (RMN), tendo as suas dinâmicas fortemente
} 
capital do estado (Natal), em decorrência da maior complexidade do mercado, as atividades hegemônicas marginais dividem espaço com as superiores puras.

No tocante ao circuito inferior, identificamos 967 atividades, das quais as principais são: comercialização de produtos alimentícios, bebidas e fumo; de tecidos, artigos de vestuário, calçados, plástico; manutenção e reparação de veículos automotores; comercialização de material de construção, artesanato, ração para animais; de veículos, peças e motocicletas; e produção de prémoldados. Destas, as mais recorrentes no eixo rodoviário são as de comercialização de produtos alimentícios, bebidas e fumo (mercadinhos, lanchonetes, bares) e as de manutenção e reparação de veículos automotores (oficinas de conserto de veículos e/ou de motocicletas, borracharias). Vale frisar que, no ramo da comercialização de veículos, peças e motocicletas, há pequenos comércios de peças para veículos e/ou para motocicletas, mas também comércio em que o responsável compra tratores ou veículos velhos, repara-os e, assim, os vende, com pagamento preferencialmente à vista ou parcelado no crédito pessoal, mediante assinatura de notas promissórias.

Assim, a economia urbana do eixo rodoviário Natal-Caicó é marcada pela proeminência quantitativa das atividades do circuito inferior. Contudo, esse destaque é também qualitativo, pelo fato de tais atividades serem importantes dos pontos de vista social, econômico e territorial. No presente artigo, analisamos detidamente a proeminência qualitativa do circuito inferior da economia urbana.

\section{ASPECTOS PARA SE COMPREENDER A IMPORTÂNCIA DO CIRCUITO INFERIOR DA ECONOMIA URBANA}

Atentamos para a análise da importância do circuito inferior da economia urbana devido a, basicamente, dois motivos. Primeiro, ao fato de o território não ser usado homogeneamente, mas, sim, por diferentes possibilidades e intencionalidades. Além da economia hegemônica, que valoriza a burocracia organizacional, a intensidade de capital e a padronização de serviços modernos e raros ofertados em determinados centros urbanos, existe, na totalidade da dinâmica territorial, a economia não hegemônica, cujas características são a criatividade e a densidade comunicacional da organização de suas atividades e a multiplicidade de tarefas desenvolvidas em todas as cidades, sejam elas pequenas, médias ou grandes - em termos demográficos - ou locais, intermediárias ou centrais - em termos funcionais. Sendo assim, é inconcebível negligenciarmos a existência de alguma dessas economias, sendo pertinente considerarmos as relações existentes entre ambas, como fazemos neste trabalho, mesmo que privilegiando, em alguns momentos da discussão, o circuito inferior, por sua proeminência quantitativa e qualitativa no território analisado. Segundo, os agentes

influenciadas pela dinâmica da capital do estado. Por isso, Macaíba e Parnamirim não se constituem em centros regionais - não obstante a complexidade dos seus mercados de trabalho, mas sim em cidades da Grande Natal. 
hegemônicos do mercado produzem oferta de força de trabalho ao expropriarem os trabalhadores dos meios de produção e desempregá-los, mas não produzem, na mesma medida, demanda de empregados em número suficiente ao de trabalhadores expropriados, fato que contribui para precarizar o mercado de trabalho. Assim, o circuito superior mais desemprega do que emprega e, quando emprega, o faz de maneira flexível, tornando o desemprego estrutural e levando muitos agentes sociais a buscarem sua sobrevivência e o uso do território por meio de ocupações precárias, situação que nos leva à apreensão da importância da economia não hegemônica de maneira ampla, isto é, dos pontos de vista social, econômico e territorial.

Não se trata aqui de compreendermos a economia desencadeada, como diz Castel ([1995] 2009, p. 593), pelos “inúteis para o mundo" ou pelos "supranumerários", que vivem em condições "nebulosas" de instabilidade e incerteza. Trata-se, sim, de refletirmos sobre as ações dos agentes do circuito inferior da economia urbana, sabendo que esse circuito econômico tem sua importância conectada aos processos de modernização econômica e urbanização do território bem como de precarização do trabalho.

Destacamos tal conexão porque, do ponto de vista socioeconômico, o circuito inferior possibilita renda e consumo para muitos trabalhadores desempregados ou nunca empregados pelo circuito superior, diante do contexto de precarização do trabalho, fazendo com que pobres possam consumir objetos técnicos modernos e, assim, satisfazer as chamadas "novas formas de escassez" (SANTOS, 1978b; OLIVEIRA, 2009; TOZI, 2012), típicas da urbanização do território alicerçada no consumismo. E, do ponto de vista territorial, o circuito inferior dinamiza o território usado de centros urbanos, sobretudo daqueles com mercado pouco complexo, como também contribui para a atratividade exercida pelos centros urbanos de maior nível funcional, ao caracterizar-se pela multiplicidade de tarefas ofertadas aos consumidores.

Além disso, o circuito inferior coexiste subordinado ao circuito superior, contribuindo, desse modo, para a reprodução ampliada da acumulação flexível de capital. Por isso, todos esses aspectos, que remetem para a importância da economia não hegemônica, inviabilizam a concepção da inutilidade dos agentes sociais dessa economia ou da não produtividade do trabalho no circuito inferior. Ao contrário, a realidade por nós estudada evidencia substancial importância desse subsistema econômico, apesar de ele manter a pobreza, na medida em que se complementa, dependentemente, com a economia hegemônica.

\section{A IMPORTÂNCIA DO CIRCUITO INFERIOR DA ECONOMIA URBANA PARA A OCUPAÇÃO DE TRABALHADORES}

Apesar de o trabalho no circuito inferior ser raramente permanente, com baixos rendimentos, ser acordado geralmente por meio de contrato pessoal entre responsável pela atividade 
e ocupado/ajudante e dar grande destaque ao trabalho familiar e autônomo, esse subsistema é grande ocupador de trabalhadores pobres e/ou sem muita qualificação na economia urbana dos países subdesenvolvidos, já que o circuito inferior ocupa poucas pessoas por unidade econômica, mas, em geral, a ocupação de trabalhadores é considerável, devido ao grande tamanho da economia não hegemônica.

Os baixos rendimentos (lucros) obtidos pelos trabalhadores responsáveis por atividades do circuito inferior decorrem dos elevados custos necessários para o desenvolvimento delas. Em todas as cidades do eixo rodoviário Natal-Caicó, o faturamento médio mensal da maioria $(39,9 \%)$ das atividades não hegemônicas era de mais de 5 salários mínimos3. Descontados gastos correntes (contas de água, luz e telefone, compra de mercadorias, tributos para registro da atividade junto ao poder público) com o desenvolvimento da atividade, o lucro obtido pela maioria $(39,2 \%)$ dos agentes do circuito inferior correspondia, geralmente, a 100\% de sua renda mensal familiar, sendo que $44 \%$ desses agentes afirmou que sua renda mensal familiar era de 1 a 2 salários mínimos. Destacamos também que, em todas as cidades, muitos $(14,9 \%)$ agentes declararam que tal lucro correspondia a menos de $50 \%$ de sua renda mensal. Esse era o caso dos que desenvolviam mais de uma atividade econômica e, assim, consideravam a atividade do circuito inferior pesquisada por nós como uma estratégia para complemento de renda.

A baixa lucratividade das atividades do circuito inferior fazia com que, na totalidade do eixo rodoviário Natal-Caicó, a maioria $(62,2 \%)$ dos agentes desse circuito utilizassem o lucro obtido com o desenvolvimento da atividade não hegemônica em investimentos na própria atividade, como a compra de mercadorias, e/ou no consumo familiar (58,8\% dos interlocutores). Havia também alguns $(4,73 \%)$ agentes que aplicavam seu lucro no desenvolvimento de outras atividades do circuito inferior ou na realização de estudos, como a compra de cosméticos para revenda ou a realização de curso superior ou técnico profissionalizante, com o escopo de aumentarem sua renda mensal e melhorarem sua situação de vida.

Apesar dessa baixa lucratividade, na maioria das atividades do circuito inferior do eixo rodoviário Natal-Caicó trabalhava mais de uma pessoa: Nos centros locais, em $71,1 \%$ das atividades pesquisadas, trabalhavam o responsável e mais uma ou duas pessoas. Na periferia oeste de Natal4, em 36,4\% das atividades, trabalhavam o responsável e mais duas pessoas. Nos centros regionais sertanejos, em uma pequena maioria $(30,4 \%)$ das atividades, trabalhava uma pessoa, além

\footnotetext{
${ }^{3}$ No período de realização da pesquisa de campo, o valor do salário mínimo no Brasil era de R\$ 678,00 em 2013 e de $\mathrm{R} \$ 724,00$ em 2014.

${ }^{4}$ A área pesquisada em Natal é uma das mais pobres da capital potiguar, marcada por baixo índice de alfabetização da população com cinco ou mais anos de idade, irrisório rendimento dos trabalhadores com dez ou mais anos de idade, bem como pela precariedade dos serviços de saneamento básico, dos equipamentos desportivos e da segurança pública. Trata-se da zona Oeste da cidade, a qual, juntamente com a zona Norte, é marcada pela pior situação socioeconômica na capital potiguar.
} 
do responsável. Contudo, em todas as cidades, também havia muitas (28,3\%) atividades desenvolvidas apenas por seus responsáveis.

Destarte, o circuito inferior destaca-se como fundamental para a vida urbana nos países subdesenvolvidos, por seu papel de abrigo da população pobre, migrante ou originária da cidade, que raramente consegue trabalhar no circuito superior. O circuito inferior ocupa os trabalhadores, geralmente, desprovidos de capital intenso para iniciar uma atividade ou de densa qualificação profissional para exercerem determinadas tarefas na economia hegemônica. São trabalhadores que sempre buscam um "jeitinho" para sua sobrevivência e encontram bem rápido uma ocupação na dilatada economia não hegemônica, cujas tarefas são bastante pulverizadas, de modo a acolher o máximo de pessoas que buscam fazer algo. Por isso, Santos (1978a) asseverara que, no circuito inferior, o fator essencial é o trabalho, enquanto no circuito superior é o capital.

Dizemos que no circuito inferior a densidade de capital não é fator essencial porque é possível iniciar e desenvolver, até certo ponto, uma atividade econômica não hegemônica com pouco dinheiro ou até sem nenhuma quantia. No eixo rodoviário Natal-Caicó, 10,8\% dos agentes do circuito inferior inquiridos afirmaram ter iniciado sua atividade econômica sem nenhuma quantia em dinheiro, ganhando os instrumentos de trabalho de um amigo ou familiar ou, ainda, herdando a atividade de um parente. Todavia, a maioria $(60,8 \%)$ dos nossos interlocutores declarou que investiu alguma quantia para iniciar sua atividade econômica, a qual variou de acordo com a situação vivenciada pelo agente social: Aqueles que nunca tiveram carteira de trabalho assinada e não ganharam ou herdaram nenhum objeto ou dinheiro de amigos ou familiares iniciaram atividade econômica com, por exemplo, R\$ 100,00; já entre aqueles que já haviam sido empregados e foram demitidos, tendo acesso ao Fundo de Garantia do Tempo de Serviço (FGTS), ou herdaram terra e/ou imóvel de parentes, vendendo a herança para investir no desenvolvimento do seu próprio negócio, alguns chegaram a despender até $\mathrm{R} \$$ 50.000,00 para começar a atividade do circuito inferior.

Acerca da qualificação profissional ou da escolaridade dos agentes do circuito inferior, é correto dizermos que, de maneira genérica, eles não têm densa qualificação, mas não que nunca estudaram. Existem agentes da economia não hegemônica que procuram iniciar seus estudos, aprofundá-los ou realizar alguma especialização para seu trabalho, no sentido de melhorarem sua situação no mercado de trabalho e, assim, suas condições de vida. Nos centros locais e nos centros regionais sertanejos do eixo rodoviário Natal-Caicó, a maioria $(47,4 \%)$ dos agentes do circuito inferior havia completado o Ensino Médio, em escola pública. Também a maioria desses trabalhadores não estava estudando no período de realização da pesquisa (85,4\%), assim como não tinha especialização para o trabalho que realizava (65\%). No entanto, havia agentes do circuito inferior $(32,8 \%)$ que tinham feito algum curso que os ajudasse a desenvolver sua atividade 
econômica, como o de vendas, o de gestão empresarial, o de culinária, de manipulação de alimentos, de informática, de bordador, de pintura de artesanato ou o de pintor automotivo, ministrados pelo Serviço Brasileiro de Apoio às Micro e Pequenas Empresas (SEBRAE), o de cabeleireiro ministrado pelo Serviço Nacional de Aprendizagem Comercial (SENAC), ou cursos possibilitados por empresas do circuito superior fornecedoras de mercadorias para a economia não hegemônica, como o de cabeleireiro ofertado pela Embeleze, o de manutenção de bicos e bombas injetoras ofertado pela Bosch, o de instalação e manutenção de gás natural veicular ofertado pela Ribeiro Gás ou, ainda, o de eletrônica ofertado preteritamente pela Philips. Do mesmo modo, havia agentes do circuito inferior $(12,4 \%)$ que estudavam visando qualificar-se profissionalmente, fazendo curso superior de Pedagogia ou curso técnico de Enfermagem.

Na periferia oeste de Natal, devido à situação de pobreza mais intensa dos agentes do circuito inferior, a maioria dos agentes desse subsistema econômico $(45,4 \%)$ havia completado o Ensino Médio, contudo havia também muitos (36,4\%) que tinham completado apenas o Ensino Fundamental. A grande maioria dos agentes estudara sempre em escola pública (72,7\%), não estava estudando $(90,9 \%)$ no período de realização da pesquisa de campo e não tinha especialização para a atividade econômica realizada (81,8\%), desenvolvendo-a de acordo com conhecimentos adquiridos com seus pais ou com colegas de trabalho.

As ocupações geradas pelo circuito inferior são precárias, mas não necessariamente não formais. Os trabalhadores desse subsistema trabalham intensivamente, com baixos rendimentos e, por vezes, em condições de trabalho não satisfatórias ou perigosas. Muitos deles não têm registro em carteira de trabalho, laborando conforme acordos verbais e sem acesso a direitos trabalhistas. Entretanto, também há trabalhadores registrados na economia não hegemônica, o que não lhes garante acesso a todos os referidos direitos, tendo-se em vista que as relações de emprego no circuito inferior também estão submetidas à flexibilização das suas condições, dependendo da conjuntura vivenciada pela atividade empregadora. Em outras palavras, se houver dificuldade monetária, o empregador não hegemônico pode fazer acordos pessoais com o empregado a fim de flexibilizar o pagamento de alguns de seus direitos, como o $13^{\circ}$ salário.

O registro em carteira de trabalho de agentes do circuito inferior vem ocorrendo de acordo com a implementação da política do Microempreendedor Individual (MEI). Assim, nos centros locais do eixo rodoviário Natal-Caicó, a maioria $(68,9 \%)$ das pessoas que estavam ocupadas no circuito inferior não tinha carteira de trabalho assinada. Na periferia oeste de Natal, na metade das atividades havia trabalhadores com registro em carteira e na outra metade não. Nos centros regionais sertanejos, em uma pequena maioria $(39,1 \%)$ das atividades não havia trabalhadores com registro em carteira de trabalho. Na totalidade do eixo rodoviário, a metade dos trabalhadores tinha grau de parentesco com o responsável pela atividade: esposo, filho, mãe, pai, tio, irmão, afilhado, 
sobrinho, primo, cunhado. Quando havia um trabalhador que era parente do responsável e um que não, geralmente o parente era o que tinha sua carteira de trabalho assinada, tendo em vista que o MEI só pode assinar a carteira de um trabalhador. Também havia atividades $(2,7 \%)$ nas quais o responsável optava por assinar a carteira do trabalhador não parente, procurando evitar, com isso, questões judiciais trabalhistas.

Em todas as cidades, a maioria das pessoas que trabalhavam com o responsável pela atividade do circuito inferior desempenhava suas funções num período de 08 a 12 horas diárias $(42,6 \%)$, de segunda-feira a sábado (39,2\%). Quando tais pessoas eram parentes do responsável, o horário de trabalho era, frequentemente, flexível, dependendo de outros afazeres do familiar ajudante, como o estudo do filho ou as tarefas domésticas da esposa, bem como dependendo de circunstâncias da atividade desenvolvida, ocorrendo a ajuda nos momentos de maior movimento nas vendas do negócio.

Tais dados evidenciam que a não formalização de relações de trabalho não deve ser considerada como peculiaridade do circuito inferior. Do mesmo modo, a flexibilização de relações empregatícias ocorre tanto nesse subsistema quanto no circuito superior. Além disso, os dados primários analisados remetem para a importância do circuito inferior na ocupação ou no emprego de familiares como também do trabalho familiar para a existência da economia não hegemônica. Esse trabalho permite que se aumente a produção sem que haja necessidade de mobilizar capital de giro para a atividade, ocorrendo, sobretudo, pela intensificação do trabalho, assim como possibilita o emprego de trabalhadores com a máxima flexibilização do pagamento de seus direitos ou a ocupação de trabalhadores sem o risco de que haja futuros encargos trabalhistas a pagar.

O destaque do circuito inferior na ocupação de trabalhadores decorre de suas características estruturais, isto é, de níveis de capital e tecnologia e forma de organização. As atividades desse subsistema não são marcadas por altos níveis de capital e tecnologia, mas, em contrapartida, têm tarefas bastante pulverizadas e ofertam uma multiplicidade, sobretudo, de comercializações de mercadorias e serviços, fazendo com que a divisão do trabalho e a complexidade econômica nesse circuito econômico seja consideravelmente densa. Por isso, McGee (1971) afirmou que tal economia é autoinflacionária, isto é, quanto mais pessoas entram em suas atividades, mais o mercado se expande, já que a multiplicidade de atividades favorece a criação de ofícios, expandindo as ocupações.

A ocupação no circuito inferior pode ocorrer por necessidade, por parte de desempregados ou nunca empregados pelo circuito superior, sendo, dessa maneira, a atividade não hegemônica a única ou a principal fonte de renda de famílias, ou pode ocorrer por complementação de renda, por empregados, geralmente, do circuito superior que buscam desencadear atividades familiares no circuito inferior, para amplificar a renda mensal de sua família. 
Nesses termos, destacamos que, na periferia oeste de Natal, a maioria $(63,6 \%)$ dos agentes do circuito inferior já havia trabalhado com registro em carteira de trabalho; nos centros locais, a maioria $(53,3 \%)$ nunca trabalhara com registro em carteira, sempre trabalhando sem ter acesso a determinados direitos trabalhistas, como férias e $13^{\circ}$ salário; nos centros regionais sertanejos, $47,8 \%$ nunca trabalhara com registro em carteira, enquanto $42,4 \%$ tinha ou tivera algum registro em sua carteira de trabalho. Em todas as cidades, os trabalhadores que já haviam sido registrados e não estavam mais nessa situação frisaram motivos para isso, como: problemas de saúde que impediam o trabalho em ritmo veemente, conforme exigido por empresas do circuito superior; demissão em decorrência de problemas financeiros enfrentados pela empresa empregadora; liberdade para trabalhar no seu próprio negócio, quanto quisesse ou necessitasse, da maneira como acreditasse ser a melhor e com horários flexíveis; comodidade de não ter que se deslocar, diariamente, para outra cidade para trabalhar como empregado, ocupando-se na cidade onde reside, próximo de sua casa e de sua família; preferência dada para assistir o companheiro ou familiar no desenvolvimento do negócio da família; aprovação em concurso público na cidade em que reside, colocando-o na condição de estatutário e dando-lhe a possibilidade de desenvolver atividade do circuito inferior como estratégia de complemento de renda.

Principalmente para os trabalhadores que desenvolvem atividade não hegemônica por necessidade, o circuito inferior se constitui em uma importante "estratégia de sobrevivência". É importante frisar que esse conceito não tem hoje a mesma conotação que tivera quando de sua proposição. Na década de 1970, devido à elevação da exploração e da exclusão dos trabalhadores pelos agentes hegemônicos do capital, Duque (1973) propôs o conceito de "estratégias de sobrevivência”, o qual, segundo Quijano (2005, p. 484), teve grande aceitação por pesquisadores da dinâmica socioeconômica dos países subdesenvolvidos devido a “[...] imensa massa de trabalhadores que estava excluída do emprego assalariado e, consequentemente, engrossava a massa de população empobrecida". Nesse período, a sobrevivência dessa "massa" de trabalhadores era entendida como a satisfação de necessidades básicas ou mínimas para a vida, como alimentar-se e vestir-se. Hoje, diante da força persuasiva das grandes empresas do circuito superior, que determinam e dominam a propagação do consumismo de objetos modernos, a sobrevivência dos trabalhadores pobres é mais do que comer e se vestir, incluindo também consumir tais objetos. Assim sendo, por meio do circuito inferior, muitos trabalhadores vêm conseguindo sobreviver diante das novas formas de escassez. 


\section{A IMPORTÂNCIA DO CIRCUITO INFERIOR DA ECONOMIA URBANA PARA O CONSUMO DE OBJETOS MODERNOS}

A ideia de escassez é dinâmica e ligada à noção de pobreza. Não devemos considerar tal ideia e tal noção como estáticas, nem mesmo como homogêneas em todas as formações sociais ou em todos os subespaços de dado território nacional.

De maneira geral, no território brasileiro, a escassez é, hoje, produzida sob duas vertentes: aquela resultante da falta de mercadorias ou objetos essenciais à vida individual e coletiva, como alimentos, vestimentas e moradia; e a resultante da força da propaganda e do crédito, cuja falta é de bens modernos essenciais à vida alicerçada no consumismo, como eletroeletrônicos. Nesse sentido, o circuito inferior apresenta-se como importante estratégia econômica para a obtenção de renda que possibilite, da maneira mais significativa possível, a sobrevivência moderna, que tem, em seu conteúdo, necessidades de consumo de objetos do período atual. Do mesmo modo, o consumo desses objetos é também um fator importante para a expansão da economia não hegemônica, tendo em vista que há atividades dessa economia que comercializam cópias de tais objetos ou os utilizam para prestar novos serviços a seus clientes, o que amplifica a multiplicidade de atividades e a divisão do trabalho no circuito inferior.

Os agentes do circuito inferior do eixo rodoviário Natal-Caicó vêm procurando sobreviver modernamente, gastando parte de sua renda com demandas consumistas de objetos técnicos modernos. Dependendo da situação de pobreza desses agentes, o nível de consumo dos referidos objetos pode ser maior ou menor e, assim, as novas formas de escassez podem ser mais ou menos sanadas.

Nos centros locais e nos centros regionais sertanejos pesquisados, a maioria dos agentes do circuito inferior residia em casa própria (60\% e 64,1\%, respectivamente), constituindo família com 4 ou com 3 pessoas (60\% e 54,3\%, respectivamente). Nos centros locais, todos os agentes possuíam televisão e geladeira, e quase todos $(97,8 \%)$, DVD e celular. Muitos $(77,8 \%)$ também possuíam máquina de lavar roupa e antena parabólica. Já nos centros regionais sertanejos, todos os agentes possuíam televisão; quase todos (99\%), geladeira, celular e DVD; e muitos possuíam máquina de lavar roupa (70,6\%), computador com acesso à internet $(67,4 \%)$ e aparelho de som $(65,2 \%)$.

$\mathrm{Na}$ periferia oeste de Natal, a maioria $(45,4 \%)$ dos agentes do circuito inferior residia em casa alugada, com família constituída por 4 ou por 2 pessoas (27,3\%). Todos possuíam televisão, geladeira e celular, destacando-se também a presença de DVD (91\%), aparelho de som e máquina de lavar roupa $(72,7 \%)$ na residência de muitos dos trabalhadores da economia não hegemônica.

Assim sendo, fica explicitado que a situação de pobreza dos agentes do circuito inferior, nos centros locais e nos centros regionais sertanejos, parece ser um pouco menos grave que a dos agentes da periferia oeste de Natal, tendo-se em vista que aqueles, em sua maioria, moram em casa 
própria, enquanto estes pagam aluguel. Em todas as cidades, o circuito inferior apresenta-se como possibilidade de obtenção ou complemento de renda para a compra de eletrodomésticos para equipar a residência dos trabalhadores da economia não hegemônica bem como para o consumo de eletroeletrônicos para satisfazer necessidades individuais desses trabalhadores ou para utilizar tais aparelhos no desenvolvimento das atividades não hegemônicas pelas quais são responsáveis.

Destacamos também que o circuito inferior não é mero gerador de renda para ser gasta no circuito superior com o consumo de objetos modernos. Existem atividades não hegemônicas que comercializam cópias desses objetos, a preços mais baratos, e, desse modo, atendem a necessidades da vida contemporânea da maioria da população, as quais “[...] incluem uma diversidade de itens técnico-cientifícos-informacionais [...]" (TOZI, 2012, p. 45). Outrossim, existem atividades do circuito inferior que utilizam objetos técnicos modernos para inovar nos serviços que prestam a seus clientes, complexificando, assim, a diversidade de atividades não hegemônicas existentes. Por isso, Santos (1990) asseverou que o atendimento de necessidades contemporâneas da maioria da população explica o funcionamento de circuitos produtivos ou distributivos do subsistema não superior da economia urbana, por meio dos quais muitas pessoas, pobres ou da chamada classe média, acessam produtos modernos.

Em suma, seja como gerador de renda ou como comercializador de mercadorias ou serviços modernos, o circuito inferior é importante, nos dias atuais, para a produção e a ampliação das novas formas de escassez, na medida em que ajuda a manter o consumismo e a pobreza estrutural.

\section{A IMPORTÂNCIA DO CIRCUITO INFERIOR DA ECONOMIA URBANA PARA O PERDURAR E A REVELAÇÃO DA POBREZA}

Os papéis do circuito inferior de acolher desempregados ou não empregados pelo circuito superior e de contribuir para o destaque do consumismo, na atualidade, podem levar algumas pessoas a imaginar que a permanência duradoura desse subsistema seja algo que se impõe e que é inevitável na dinâmica econômica das cidades dos países subdesenvolvidos. O problema é que o circuito inferior, além de ser um provedor de rendas e de ocupações e atender demandas da maioria dos consumidores, tem também a função de mantenedor da pobreza, de coletor da poupança popular (SANTOS, 1978a), que é drenada para o circuito superior via intermediários ou instituições sobretudo comerciais ou financeiros.

Além de sua subordinação ao circuito superior, o circuito inferior faz perdurar a pobreza pela precariedade das ocupações que gera. Afora baixos rendimentos, longas jornadas de trabalho, falta de acesso a direitos trabalhistas e difíceis condições de labor, grande parte dos agentes da economia não hegemônica desenvolve atividades sem nenhuma perspectiva de descanso ou de 
acesso a algum direito social no futuro. Isso devido a não terem condições de contribuir para a previdência nacional e, desse modo, não saberem se haverá alguma possibilidade de aposentadoria e repouso após muitos anos de trabalho.

Em todas as cidades do eixo rodoviário Natal-Caicó, a maioria (54\%) desses agentes não recolhia taxas do Instituto Nacional do Seguro Social (INSS) para sua aposentadoria. Contudo, há de se destacar que a política do MEI fez com que muitos $(43,9 \%)$ agentes da economia não hegemônica realizassem tal recolhimento, devido a cumprirem seus deveres tributários de empreendedores. Talvez essa política seja intensificada e aperfeiçoada no futuro próximo, no sentido de garantir direitos sociais para a maioria dos trabalhadores, senão para todos, podendo, assim, minimizar a incerteza que ainda marca o futuro dos agentes do subsistema inferior e contribuir para que o dinamismo econômico não faça perdurar a pobreza estrutural. Porém a palavra "talvez" indica uma suposição, sendo que, nos dias atuais, os impactos da política do MEI ainda necessitam ser ampliados e melhorados, tendo-se em vista que a maioria dos trabalhadores pobres responsáveis por micro e pequenas atividades econômicas continua sem ter acesso a garantias sociais trabalhistas.

Do mesmo modo que faz perdurar a pobreza, o circuito inferior revela a pobreza produzida pelos agentes hegemônicos do capital. Estes modernizam o território de modo seletivo e simetricamente com estruturas sociais, econômicas e políticas arcaicas, não promovendo mudanças substanciais e estruturais. Fazendo isso, tais agentes aumentam a lucratividade de suas atividades econômicas pela diminuição do número de empregos e pelo aumento da exploração do trabalho, tornando estrutural, ou seja, não provisória, a situação de pobreza da maioria dos trabalhadores, e, cada vez mais intensa, em termos de escassez de produtos tradicionalmente necessários ao bemestar humano e social e de produtos modernos tornados necessários na contemporaneidade.

Vivendo nessa situação, os trabalhadores pobres buscam abrigo no circuito inferior da economia urbana, desenvolvendo várias atividades no sentido de obter sua sobrevivência e a de sua família. Destarte, a existência desse circuito econômico revela a pobreza estrutural como resultado da modernização econômica do território e, relacionada com o circuito superior, como uma estratégia para reproduzir amplamente o sistema econômico vigente.

\section{A IMPORTÂNCIA DO CIRCUITO INFERIOR DA ECONOMIA URBANA PARA A REPRODUÇÃO AMPLIADA DO SISTEMA ECONÔMICO VIGENTE}

Ao contrário do que muitos autores defendem, o trabalho desenvolvido pelos pobres não é improdutivo, e é importante para a reprodução ampliada do estágio atual do capitalismo. A produtividade dos agentes da economia não hegemônica é evidenciada pela intensidade de trabalho que a caracteriza, apesar dos baixos rendimentos que proporciona a seus agentes. No circuito 
inferior, o trabalho é, geralmente, acordado por relações não burocráticas, alicerçadas em contratos pessoais. Não obstante, os agentes desse subsistema trabalham por longas jornadas, de maneira intensa e durante todos ou quase todos os dias. Assim sendo, a produtividade do trabalho na economia não hegemônica é um fato observado por nós na realidade do eixo rodoviário NatalCaicó.

Além disso, por meio do circuito inferior muitos trabalhadores obtêm renda que possibilita que consumam, juntamente com suas famílias, o que é importante para a sobrevivência da maioria dos desempregados pelo circuito superior assim como para a expansão do consumo na contemporaneidade, em termos periféricos. Via atividades não hegemônicas, os trabalhadores pobres, que não têm dinheiro para consumir objetos modernos no circuito superior, o fazem no circuito inferior. Do mesmo modo, por meio dessas atividades localizadas na periferia das cidades, os pobres, que não têm condições de se deslocar, com frequência, para o centro, atendem suas necessidades diárias de consumo no circuito inferior, aproveitando-se das flexibilizações que marcam a organização não ou pouco burocrática desse subsistema, como a pechincha e o fiado.

Por gerar renda para muitas pessoas, o circuito inferior também é importante para a monetarização da economia dos países subdesenvolvidos. Essa economia é abalizada pela existência de muitas atividades não hegemônicas que ocupam trabalhadores sem necessariamente assalariá-los, o que não quer dizer que sua população não participe de uma economia monetarizada. Devido ao fato de a maioria das negociações no circuito inferior ser realizada em dinheiro, pode-se constatar certa generalização de dinheiro líquido na economia dos referidos países (SANTOS, 1978a).

Outrossim, os agentes do circuito inferior não conseguem acumular grandes quantidades de dinheiro, por terem de gastar a maior parte de seu faturamento com o pagamento de custos correntes com o desenvolvimento de suas atividades, ficando, assim, com baixos rendimentos mensais. Isso faz com que haja substancial circulação de moeda nas negociações feitas no circuito inferior ou desse subsistema com o circuito superior, o que ocasiona o perdurar da situação de pobreza dos agentes daquele circuito, devido à dificuldade de acumularem capital. O pouco capital que eles conseguem economizar é, geralmente, investido no desenvolvimento ou no melhoramento do próprio negócio.

Sendo assim, nos centros locais e nos centros regionais sertanejos do eixo rodoviário Natal-Caicó, a maioria (51,1\% e 40,2\%, respectivamente) dos agentes do circuito inferior declarou que tinha ou já havia tido alguma reserva de dinheiro, conseguida com o desenvolvimento da atividade, com a realização de empréstimo bancário ou com o recebimento de herança. Na periferia oeste de Natal, uma pequena maioria $(54,5 \%)$ declarou nunca ter tido tal reserva, enquanto $45,4 \%$ responderam positivamente. Em todas as cidades, a maioria $(73,8 \%)$ dos agentes que tinha ou já 
havia tido alguma reserva de dinheiro a utilizou para investir na atividade não hegemônica desenvolvida, comprando mercadorias, instrumentos ou equipamentos de trabalho e realizando a manutenção destes bem como construindo ou reformando o estabelecimento comercial.

A importância do circuito inferior para a reprodução ampliada do sistema capitalista também é explicitada pelas características relacionais que esse subsistema mantém com o circuito superior. Esses circuitos se complementam e concorrem no mercado, sendo que, para o circuito inferior, a complementaridade com o circuito superior pode ser entendida como sinônimo de subordinação. Isso porque os agentes da economia hegemônica determinam e dominam as variáveis-chave do período atual (técnica, ciência, informação, finanças, consumo) e, à medida que essas variáveis são incorporadas pelo circuito inferior, drenam boa parte dos lucros obtidos pelos trabalhadores pobres para a "poupança do circuito superior".

Nesse sentido, sublinhamos que as atividades do circuito inferior, longe de serem excrescências e mero depósito do exército de desempregados pelo circuito superior, são adequadas para o processo de acumulação global e da expansão capitalista, e, por seu lado, reforçam a tendência à concentração de renda. Por isso, Santos (1978a) asseverou que, além de abrigar pobres, o circuito inferior serve para expandir ganhos monetários e financeiros do circuito superior, tendo em vista a relação de dependência daquele circuito a este.

Dessa maneira, pela produtividade dos seus trabalhadores, por gerar renda para muitas pessoas e estender o consumo moderno aos pobres, por contribuir para a monetarização da economia urbana dos países subdesenvolvidos e por relacionar-se, dependentemente, com o circuito superior, evidenciamos o papel importante da economia não hegemônica na reprodução ampliada do sistema econômico vigente.

A contribuição do circuito inferior para essa reprodução ampliada permite que suas atividades sejam proeminentes em determinadas cidades, de forma que podemos dizer que a economia não hegemônica chega, de certo modo, a micro-organizar espaços. Contudo isso só é possível porque a macro-organização do território compete ao circuito superior, que comanda a economia e a instalação seletiva de capitais fixos no espaço nacional. De todo modo, o circuito inferior também tem sua importância territorial, sobretudo nas cidades onde o mercado é menos complexo, embora não deixe de ser determinado pelas forças hegemônicas do capital.

\section{A IMPORTÂNCIA DO CIRCUITO INFERIOR DA ECONOMIA URBANA PARA A DINÂMICA TERRITORIAL URBANA}

As atividades do circuito superior da economia urbana não se localizam densamente em todas as cidades do Rio Grande do Norte, nem mesmo em todo o território intraurbano. Os agentes do circuito superior selecionam os lugares mais adequados para a obtenção de grandes 
lucratividades e, assim, implementam seus negócios, fazendo com que os lugares não selecionados sejam caracterizados pela predominância da economia desenvolvida pelos pobres. Não obstante, os lugares não selecionados não são renegados pelo capital hegemônico, já que a economia dos pobres coexiste com o circuito superior, contribuindo para a concentração de renda por este e para a reprodução ampliada do desigual sistema econômico vigente.

No atual estágio do processo de urbanização do Rio Grande do Norte, o circuito superior existe apenas numa pequena parte do território urbano estadual e do eixo rodoviário Natal-Caicó, sendo que, na totalidade da dinâmica econômica das cidades, predomina a expansão do circuito inferior, fato revelador da amplificação da pobreza estrutural. Sendo assim, a urbanização potiguar é fundamentada na coexistência, de maneira dependente, da economia não hegemônica em relação à hegemônica.

Embora o circuito inferior seja importante para a dinâmica econômica de todas as cidades do Rio Grande do Norte e, particularmente, do eixo rodoviário Natal-Caicó, seu destaque é maior nas cidades onde o mercado de trabalho é menos complexo, ou seja, onde as atividades do circuito superior são menos presentes e o número de empregos gerados é menor.

Assim, nos centros locais do eixo rodoviário Natal-Caicó, a maioria dos agentes do circuito inferior trabalhava na atividade há mais de 20 anos (26,7\%) ou de 10 a 15 anos (17,8\%). Também havia muitos $(15,5 \%)$ agentes que estavam trabalhando na atividade havia menos de 01 ano. Na periferia oeste de Natal, a situação encontrada foi oposta: a maioria $(36,4 \%)$ trabalhava na atividade havia menos de 01 ano. Em seguida, se destacaram aqueles que trabalhavam na atividade havia 05 a 10 anos ou 15 a 20 anos $(18,2 \%)$. Nos centros regionais sertanejos, os dados evidenciam uma situação bastante heterogênea: uma pequena maioria de trabalhadores desenvolvia atividade do circuito inferior havia mais de 20 anos $(22,8 \%)$ ou de 05 a 10 anos $(17,4 \%)$, sendo seguida por uma porcentagem considerável de trabalhadores que eram agentes da economia não hegemônica havia menos de $01(15,2 \%)$ ou havia 01 a 02 anos (10,9\%). Tais dados devem ser cruzados com os dos trabalhadores que já tinham tido registro em carteira de trabalho: na periferia de Natal, estes foram a maioria (63,6\%); nos centros locais, não $(44,4 \%)$; nos centros regionais sertanejos, representaram $42,4 \%$ dos inquiridos, porcentagem um pouco menor que a de trabalhadores que nunca tinham trabalhado com registro em carteira $(47,8 \%)$.

Assim, explicitamos que, em Natal e, em menor medida, nos centros regionais sertanejos, os desempregados pelo circuito superior estão, há algum tempo, desenvolvendo atividade no circuito inferior em busca da sua sobrevivência e da de sua família. Já nos centros locais, majoritariamente, e nos centros regionais sertanejos, em menor medida, os trabalhadores, geralmente, já ingressam no mercado de trabalho via circuito inferior, desenvolvendo há mais tempo atividade na economia não hegemônica. Esses dados remetem para as diferentes dinâmicas 
das cidades: em Natal e nos centros regionais sertanejos, devido à maior complexidade do mercado de trabalho, a população residente tem mais possibilidades de conseguir emprego no circuito superior ou com registro em carteira de trabalho, ao contrário do que ocorre nos centros locais, onde predominam as atividades do circuito inferior e, assim, as oportunidades de emprego são menores, restando, na maioria das vezes, as ocupações.

A configuração do mercado de trabalho das cidades locais evidencia o destaque do circuito inferior na micro-organização do espaço. Esse destaque ocorre por esse circuito contribuir para a expansão do território usado urbano, com a acentuação de moradores, de atividades econômicas e de trabalhadores ocupados na cidade; a diversificação do mercado, com o desenvolvimento crescente de novas atividades produtivas, comerciais e de serviços; a integração do mercado, com o abastecimento de mercadorias da economia não hegemônica pelo circuito superior e com a rede de solidariedade orgânica mantida entre agentes do circuito inferior; a banalização de variáveis-chave do período atual, determinadas e dominadas pela economia hegemônica.

Sabendo dessas contribuições, Silveira (2007, p. 11) chegou a afirmar que, de certo modo, graças à contiguidade, à soma de ofertas e demandas e à densidade comunicacional, o circuito inferior "[...] reserva para si uma certa capacidade de comando [...]" das cidades locais ou das áreas menos valorizadas dos centros urbanos de maior destaque demográfico e funcional. Entretanto, levando em consideração o abastecimento do circuito inferior pelo circuito superior e a determinação das variáveis-chave do período atual por esse subsistema, acreditamos não ser pertinente afirmar que o circuito inferior comande a dinâmica econômica, mesmo das cidades locais. Para nós, o que é real é a proeminência quantitativa e qualitativa desse circuito no território usado urbano nacional. Tal proeminência, apesar de evidenciar "certo destaque" do circuito inferior, também traz à tona sua subordinação ao circuito superior, sendo este o verdadeiro comandante da economia, seja na escala macro seja na micro.

Além de todas as contribuições já destacadas do circuito inferior para a dinâmica territorial urbana, destacamos também sua importância para a polarização e a atração que algumas cidades podem exercer sobre as outras cidades que lhe são próximas ou sobre áreas municipais associadas. Essa importância ocorre pela multiplicidade de atividades que a economia não hegemônica traz à tona, o que, ao lado dos serviços raros ofertados pelo circuito superior, confere destaque a determinados centros urbanos em dado contexto territorial. Assim, enfatizamos, junto com Oliveira (2009, p. 256), que hoje não é pertinente acreditar que apenas o circuito superior seja importante para a polarização urbana; as atividades do circuito inferior também vêm participando ativamente “dos múltiplos fluxos que estabelecem a polarização de uma cidade [...]”. 
Apesar de todas essas discussões lastreadas por dados primários, ainda há autores, particularmente na geografia potiguar, que negligenciam o importante papel da economia não hegemônica na dinâmica territorial.

Concordando com o pensamento de Clementino (1996), acerca das receitas municipais e do grau de dependência dos pequenos municípios do Nordeste brasileiro5, Gomes (2007, p. 18), ao coordenar pesquisa sobre a dinâmica socioeconômica das pequenas cidades do Rio Grande do Norte, asseverara que tal dinâmica está sendo promovida pelas políticas compensatórias, tendo em vista que, com a crise de economias tradicionais, como a pecuária e a cotonicultura, um dos principais desafios nessas cidades é o do desemprego e que “[...] a principal fonte de renda [...] [nas] pequenas cidades consiste no serviço público, nas aposentadorias dos idosos e nos programas de transferência de renda do Governo Federal".

Essa concepção reduz a totalidade da dinâmica territorial urbana, negligenciando outros aspectos e outras ações para além das chamadas "políticas compensatórias". Dentre esses outros aspectos, frisamos as relações existentes entre os circuitos da economia urbana nas cidades do Rio Grande do Norte, com a proeminência, sobretudo nas cidades locais, do circuito inferior, o qual é importante social, econômica e territorialmente, conforme estamos analisando.

Em nenhum momento de seu estudo, Gomes (2007) analisa a economia não hegemônica, ou mesmo suas relações com o circuito superior da economia urbana. O que faz é atentar para as "atividades terciárias" existentes nas cidades, destacando que elas são "informais" e, portanto, incapazes de absorver toda a mão de obra desempregada, devido a seu caráter fortemente familiar. Constituem, assim, uma "economia sem produção", isto é, incapaz de garantir a reprodução social, atendendo somente necessidades imediatas.

Essa abordagem é, a nosso ver, bastante equivocada, pois setoriza a economia não hegemônica, não considera seu caráter produtivo e sua importância socioeconômica, já que, por meio dela, muitos trabalhadores e suas famílias obtêm renda e a possibilidade de consumir. Sendo assim, a referida análise também acaba por negligenciar a contribuição do circuito inferior para a dinamicidade das cidades locais. Preocupante é saber que essa é a compreensão de uma das pesquisadoras que mais estuda a pobreza no Rio Grande do Norte em termos geográficos, o que nos leva a pensar que a geografia potiguar não vem se dando conta de que as cidades locais são, sobretudo, espaços da contiguidade, cuja dinamicidade é mais a matriz da vida social do que o reino da velocidade, conforme destaca Silveira (2011). É, portanto, imprescindível que se atente para a

\footnotetext{
${ }^{5}$ Para Clementino (1996, p. 06), na maioria dos pequenos municípios nordestinos a dinâmica econômica é frágil, no sentido de gerar quantitativa e qualitativamente empregos e renda para grande parte dos trabalhadores, bem como no de propiciar "[...] uma base tributável própria para reduzir sua dependência da União". Assim, a citada autora opina que são os gastos públicos, com aposentadorias, pensões e transferências de receitas governamentais constitucionais, que produzem certa circulação monetária e, portanto, garantem o funcionamento do pequeno comércio local.
} 
totalidade dos sistemas de objetos e de ações que configuram os territórios analisados, considerando a pobreza como uma situação grave de escassez, mas também como uma situação ativa de uso resistente do território diante das desigualdades produzidas pelos agentes hegemônicos do mercado.

\section{CONSIDERAÇÕES FINAIS}

O circuito inferior também evidencia a importância do território usado como fator de desigualdades e viabilizador de alternativas e resistências. A existência expandida desse circuito revela as desiguais condições do território usado nacional, que incentivam o desenvolvimento de atividades da economia não hegemônica, devido a esse território não estar apto a fornecer, para a maioria dos habitantes, “[...] as qualidades mínimas a uma vida digna” (TOZI, 2012, p. 235).

Mas o território usado não é apenas desigualdades; é também caracterizado pela resistência dos agentes do circuito inferior diante da grave situação de pobreza que enfrentam, assim como pelas alternativas de mudança do sistema econômico vigente que a solidariedade comunicacional desses agentes explicita. A diversidade do território usado, com a existência, inclusive, de áreas desvalorizadas pelos agentes hegemônicos do mercado possibilita aos trabalhadores pobres abrigarem-se nele, ao desenvolverem ações que os fazem participar da divisão do trabalho comandada pelo circuito superior bem como lhes permite resistir a algumas "consequências da racionalidade hegemônica" (OLIVEIRA, 2009), ao calcarem suas ações na densidade comunicacional.

Na cidade, a diversidade do território usado é maior, sendo o mercado mais complexo e as possibilidades de resistência mais amplas. Por isso, ela atrai trabalhadores pobres que, desempregados ou não empregados pelo circuito superior, desenvolvem atividades econômicas criativas e nada ou pouco burocráticas, tendo na dinâmica territorial um fator ativo para sua sobrevivência e para a resistência a algumas imposições da economia hegemônica.

Destacamos a dinâmica territorial como fator ativo da vida dos homens pobres levando em conta a contiguidade e a proximidade que a cidade propicia aos diferentes agentes sociais e às desiguais ações. É nesse espaço que coexistem micro e pequenos negócios com grandes empresas, atividades tradicionais com atividades modernas, trabalhadores assalariados com trabalhadores cujos rendimentos são flexíveis, empregados com desempregados ou ocupados, dentre outras relações desiguais e contraditórias, porém combinadas. Essa dinamicidade é fator ativo da vida pobre, porque fundamenta a expansão e a manutenção das atividades do circuito inferior concatenadas aos ditames do circuito superior.

Finalizamos esta análise sublinhando que mudanças estruturais nas relações e no mercado de trabalho já estão em curso e que, num futuro próximo, haverá condições de se produzir a urbanização sem que a pobreza estrutural seja também produzida de maneira expansiva. Contudo, 
devemos realçar que, enquanto não predomina o "mercado socialmente necessário" (RIBEIRO, 2005), o circuito inferior é e será importante para viabilizar a sobrevivência da maioria dos trabalhadores e para explicitar a tensão ou a crise vivenciada no mercado de trabalho e na sociedade, em suma no território usado.

Além disso, temos esperança de que o pensamento de Quijano (2005), quando assevera que a economia não hegemônica não é mera estratégia de sobrevivência mas também uma forma de resistência a nexos da Globalização e pode ser uma "alternativa para a ruptura com o sistema econômico hegemônico", se confirme da maneira mais intensa e rápida possível.

\section{REFERÊNCIAS}

ANDERSON, N. Our industrial urban civilization. London: Asia Publishing House, 1964.

ARMSTRONG, W.; McGEE, T. G. Revolutionary change and the third world city: a theory of urban involution. Civilisations, 18 (3), 1968.

BICUDO JÚNIOR, E. C. O circuito superior marginal: produção de medicamentos e o território brasileiro. 2006. Dissertação (Mestrado em Geografia Humana), Universidade de São Paulo, São Paulo.

BIENEFELD, M. The informal and the peripheral capitalism: the case of Tanzania. Institute of Development Studies Bulletin, v. 6, n. 3, p. 53-73, 1975. Disponível em: <http://onlinelibrary. wiley.com/doi/10.1111/j.1759-5436.1975.mp6003008.x/pdf>. Acesso em 10 mar. 2015.

BOEKE, J. H. Economics and economic policy of dual societies, as exemplified by Indonesia. Haarlem: Tjeenk Willink, 1953.

CASTEL, R. As metamorfoses da questão social: uma crônica do salário. Tradução de Iraci D. Poleti. Petrópolis: Vozes, [1995] 2009.

CLEMENTINO, M. L. M. Receitas municipais e grau de dependência dos pequenos municípios do Nordeste. In: Encontro Nacional da Apipsa, Anais... Campina Grande, 1996. Disponível em: $<$ http://unuhospedagem.com.br/revista/rbeur/index.php/anais/article/view/179 4/1762>. Acesso em 28 ago. 2015.

DAVID, V. C. Território usado e circuito superior marginal: equipamentos médico-hospitalares em Campinas, Ribeirão Preto e São José do Rio Preto (SP). 2010. Dissertação (Mestrado em Geografia Humana), Universidade de São Paulo, São Paulo.

DUQUE, J. Las estrategias de sobrevivencia de las unidades familiares del setor popular urbano. Santiago do Chile: Proelce, 1973.

GEERTZ, C. Peddlers and princes: social change and economic modernization in two Indonesian towns. Chicago: The University of Chicago Press, 1963. Disponível em: < http://hypergeertz. jku.at/GeertzTexts/Peddlers_Princes.htm>. Acesso em 04 mar. 2015. 
GOMES, R. C. C. (Coord.) Relatório técnico "Planejamento, gestão do território e desenvolvimento socioespacial nas pequenas cidades do Rio Grande do Norte. Natal: UFRN, 2007.

GUNDER FRANK, A. Le Brésil dans l'impasse. Partisans, Paris, n. 26-27, 1968.

LEWIS, W. A. Economic development with unlimited supplies of labour. Manchester: School of Economics and Social Studies, 1954. Disponível em: <ftp://ftp.uic.edu/pub/depts/econ/wpaper /cchis/docs533/Economic\%20Development\%20with\%20Unlimited\%20Supplies\%20of\%20Labour \%20-\%20Arthur\%20Lewis.pdf>. Acesso em 04 mar. 2015.

McGEE, T. G. The urbanization process in the Third World: explorations in search of a theory. Londres: G. Bell \& Sons, 1971.

McGEE, T. G. Hawkers in Hong Kong: a study of planning and policy in a third world city. Hong Kong: Centre of Asian Studies, University of Hong Kong, 1973.

MONTENEGRO, M. R. Globalização, trabalho e pobreza no Brasil metropolitano. $O$ circuito inferior da economia urbana em São Paulo, Brasília, Fortaleza e Belém. 2011. Tese (Doutorado em Geografia Humana), Universidade de São Paulo, São Paulo.

NUN, J. Superpoblación relativa, ejército industrial de reserva y masa marginal. Revista Latinoamericana de Sociología, Buenos Aires, 5 (2), 1969. Disponível em: <http://repositorio. cepal.org/bitstream/handle/11362/7934/S7100908_es.pdf?sequence=1>. Acesso em 28 fev. 2015.

OLIVEIRA, F. A economia brasileira: crítica à razão dualista. Estudos CEBRAP, São Paulo, v. 2, p. 03-82, 1972.

OLIVEIRA, M. A. A. Trabalho informal e redes sociais: os camelôs da Praça da Matriz em Manaus. 2009. Dissertação (Mestrado em Sociologia), Universidade Federal do Amazonas, Manaus.

QUIJANO, A. Mano de obra marginal y polo marginal de la economía. Santiago do Chile: CEPAL, 1969.

QUIJANO, A. Sistemas alternativos de produção? In: SANTOS, B. S. (Org.) Produzir para viver: os caminhos da produção não capitalista. Tradução de Manuel del Pino. Rio de Janeiro: Civilização Brasileira, 2005. pp. 475-514.

RIBEIRO, A. C. T. Território usado e humanismo concreto: o mercado socialmente necessário. In: X Encontro de Geógrafos da América Latina: por uma Geografia Latino-Americana: do Labirinto da Solidão ao Espaço da Solidariedade. Anais... São Paulo: USP, 2005.

SANTOS, M. Une nouvelle dimension dans l'étude des réseaux urbains dans les pays sousdéveloppés. Annales de Géographie, t. 79, n. 434, p. 425-445, 1970. Disponível em: <http://www. persee.fr/web/revues/home/prescript/article/geo_00034010_1970_num_79_434 15135>. Acesso em: 10 mar. 2015.

SANTOS, M. Dimension temporelle et systèmes spatiaux dans les pays du Tiers Monde. TiersMonde, tome 13, n. 50, Modernisations et "espaces dérivés", sous la direction de Milton Santos, p. 247-268, 1972. Disponível em: <http://www.persee.fr/web/revues/home/prescript/issue/tiers_00407 356_1972_nu m_13_50>. Acesso em: 08 mar. 2015. 
SANTOS, M. O espaço dividido: os dois circuitos da economia urbana dos países subdesenvolvidos. Rio de Janeiro: Livraria Editora Francisco Alves, 1978a.

SANTOS, M. Pobreza urbana. São Paulo, Recife: Hucitec, UFPE, Comissão Nacional de Regiões Metropolitanas e Política Urbana, 1978b.

SANTOS, M. Involução metropolitana e economia segmentada: o caso de São Paulo. In: RIBEIRO, A. C. T.; MACHADO, D. B. P. (Org.) Metropolização e rede urbana: perspectivas dos anos 90. Rio de Janeiro: IPPUR/UFRJ, 1990. pp. 79-113.

SANTOS, M. Da totalidade ao lugar. São Paulo: Editora da Universidade de São Paulo, 2008.

SILVEIRA, M. L. Crises e paradoxos da cidade contemporânea: os circuitos da economia urbana. In: X Simpurb: Trajetórias da Geografia Urbana no Brasil: Tradições e Perspectivas, Anais... Florianópolis: UFSC, 2007.

SILVEIRA, M. L. Nuevo orden espacial de la globalización: encrucijadas y horizontes. Revista de Geografia Espacios, Revista de Geografia da Universidad Academia de Humanismo Cristiano, v. 1, p. 1-17, 2011.

TOZI, F. Rigidez normativa e flexibilidade tropical: investigando os objetos técnicos no período da globalização. 2012. Tese (Doutorado em Geografia Humana), Universidade de São Paulo, São Paulo.

Trabalho enviado em 23/05/2018

Trabalho aceito em 07/01/2019 